\title{
МЕЖДУНАРОДНО-ПРАВОВАЯ ОТВЕТСТВЕННОСТЬ
}

\section{Возрождение забытой парадигмы: принцип материальной ответственности за загрязнение окружающей среды}

Абу Хена Мостофа Камал*

В данной статье затрагивается тема, к которой редко обращаются. Это сложные вопросы международного права в области охраны природы, которые имеют непосредственное отношение к принципу материальной ответственности за загрязнение окружающей среды. Чтобы ввести читателя в курс дела, в первой части данной статьи дается краткое определение принципа и его история. Далее анализируются проблемы ответственности, критериев доказанности, необходимых для установления факта загрязнения, и сроков исковой давности. Особое внимание уделено критическому взгляду на вопросы применения принципа материальной ответственности за загрязнение окружающей среды. Возможно, результаты данного исследования привлекут внимание высших органов, и будут приняты жесткие правовые меры для обеспечения защиты окружающей среды от загрязнения в будущем.

Ключевые слова: принцип материальной ответственности за загрязнение окружающей среды; правовые нормы по охране окружающей среды; принципы международных правовых норм по охране окружающей среды; принцип платности за загрязнение.

Принцип материальной ответственности за загрязнение окружающей среды заключается в официальном признании идеи о том, что загрязнитель несет затраты на принятие мер, необходимых для

* Абу Хена Мостофа Камал - лектор юридического факультета Университета Бангладеш ЭйЭсЭй. gollancz75@yahoo.com.. 
устранения загрязнения окружающей среды, произошедшего по его вине, или для снижения отрицательного эффекта на окружающую среду согласно требованиям стандартов. Необходимо отметить, что экологическое право не трактует принцип материальной ответственности за загрязнение окружающей среды как нарушение. Напротив, он благоприятствует исправительному подходу, который предусматривает возмещение экологического ущерба. Этот принцип может трактоваться как (a) стандартный принцип материальной ответственности за загрязнение окружающей среды, то есть загрязнители оплачивают мероприятия по контролю загрязнения и ликвидации последствий ухудшения состояния окружающей среды и (b) расширенный принцип материальной ответственности за загрязнение окружающей среды, то есть загрязнители оплачивают мероприятия по борьбе с загрязнением и ликвидации его последствий и выплачивают компенсацию пострадавшим сторонам.

Суть принципа материальной ответственности за загрязнение окружающей среды состоит в том, что лицо, загрязняющее воздух, воду или другую среду, должно быть ответственным за очищения загрязнений ${ }^{1}$. Как пишет профессор Фигипп Сэндз (Philippe Sands), «принцип материальной ответственности за загрязнение окружающей среды требует, чтобы стоимость ущерба от загрязнения возмещалась лицом, ответственным за загрязнение и косвенные убытки» ${ }^{2}$. Профессор Ян Янс (Jan H. Jans) определил принцип материальной ответственности за загрязнение окружающей среды как «принцип, http://multitran.ru/c/m. exe?t=2679967_1_2 ставящий в счет загрязнителя расходы на мероприятия по борьбе с загрязнением, произошедшим по вине конкретного загрязнителя, что стимулирует его сократить выбросы загрязняющих веществ и способствует поиску материалов и технологических процессов, наносящих меньший вред окружающей среде» ${ }^{3}$. Другое определение принципу материальной ответственности за загрязнение окружающей среды дает Николас де Саделеер (Nicolas de Sadeleer). Он пишет: «принцип материальной ответственности за загрязнение окружающей среды обязывает загрязнителя включать экологические издержки. Таким образом, принцип напрямую не предписывает контроль

${ }^{1}$ The Queen v. Secretary of State for the Environment and Minister of Agriculture, Fisheries and Food ex parte: H.A. Standley and Others and D.G.D. Metson and Others. Case C-293/97. ${ }^{2}$ Sands, Philippe(2002), Principles of international environmental law, Frameworks, standards and implementation, Volume 1 , Manchester University Press.

${ }^{3}$ Professor Jan H. Jans(2002), European Environmental Law, Europa Law Publishing, Second edition. 
загрязнения окружающей среды; он традиционно рассматривается как механизм распределения затрат... Принцип материальной ответственности за загрязнение окружающей среды необходимо рассматривать как превентивную норму, так как это правило способно заставить загрязнителя воздержаться от загрязнения, если издержки, распределенные в соответствии с данным принципом, представляются слишком большими для загрязнителя» ${ }^{4}$.

В деле Социальный форум Веллора против Индийского Союза $(1996)^{5}$ относительно принципа материальной ответственности за загрязнение окружающей среды сказано: «Безусловная ответственность за ущерб, причиненный окружающей среде, распространяется не только на выплату компенсаций жертвам загрязнения, но также на возмещение затрат на борьбу с ухудшением окружающей среды. Устранение ущерба, нанесенного окружающей среде, является частью процесса устойчивого развития» 6 .

В соответствии с Рекомендациями Совета (номер С(74)223) от 14 ноября 1974 года по имплементации принципа материальной ответственности за загрязнение окружающей среды «принцип материальной ответственности за загрязнение окружающей среды... подразумевает, что загрязнитель обязан нести затраты на предотвращение загрязнения окружающей среды и принятие мер по борьбе с загрязнением, введенных органами местной власти... с целью обеспечения благоприятной экологической обстановки. Иными словами, стоимость мер борьбы с загрязнением должна быть включена в стоимость товаров и услуг, производство и/или потребление которых вызывает загрязнение» 7 .

Организация экономического сотрудничества и развития (ОЭСР) впервые ввела принцип материальной ответственности за загрязнение окружающей среды в 1972 году. До этого Парижская конвенция 1960 года и Венская конвенция о гражданской ответственности

${ }^{4}$ Sadeleer ,Nicolas de (2002), Environmental Principles - From Political Slogans to Legal Rules (Translation by Susan Leubusher). Oxford University Press.

${ }^{5}$ SCALE (PIL) 1981-87 (Kuldip Sing, J.) 703 (1996).

${ }^{6}$ Упомянуто в решении: para-32,Research Foundation for Science Technology and Natural Resources Policy v. Union of India and Another, WP 657/1995 (2005.01.05), Supreme Court of India, Case No Writ Petition (C) No.657 of 1995 (With S.L.P.(C) No. 16175 and C.A. No. 7660 of 1997). Дата решения: 05/01/2005. Also quoted in Indian Council for Enviro-Legal Action v. Union of India [(1996) 3 SCC 212: JT (1996) 2 SC 196].

${ }^{7}$ Recommendation of the Council concerning the Application of the Polluter-Pays Principle to Accidental Pollution, 7 July 1989 - C(89)88/Final,internet source: http://webdomino1. oecd.org/horizontal/oecdacts.nsf/linkto/C(89)88. 
за ядерный ущерб 1963 года ставили целью продвижение принципа материальной ответственности за загрязнение окружающей среды с целью гарантировать выплату загрязнителем достаточной компенсации жертвам загрязнения. Необходимо помнить, что данный принцип не является новой концепцией; он был заложен давно в истории права. Среди древних ученых греческий философ Платон впервые выделил понятие материальной ответственности виновника загрязнения. Он говорил: «Если кто-либо преднамеренно загрязняет воды, принадлежащие другому, ... пусть он не только возместит ущерб, но также очистит ручей или пруд, содержащий эти воды...» ${ }^{8}$. Платон признавал, что вода может находиться как в частном, так и в общем владении; в обоих случаях компенсация выплачивается загрязнителем, и впоследствии к данному лицу может быть предъявлено требование возместить нанесенный ущерб. В сущности, принцип материальной ответственности за загрязнение окружающей среды является современной формулировкой давно существующей концепции. Однако основы современного правила материальной ответственности за загрязнение окружающей среды были разработаны в странах ОЭСР в 90-х годах ХХ века и были впервые вынесены на широкое обсуждение на конференции ООН по охране окружающей среды и развитию, состоявшейся в Рио-де-Жанейро в июне 1992 года. Самым ярким примером воплощения данного принципа в жизнь является американский Закон о гарантиях, ответственности, полной компенсации ущерба окружающей среде (CERCLA или Суперфонд).

Принцип материальной ответственности за загрязнение окружающей среды в основном рассматривается как принцип внутригосударственного, а не международного права; однако его часто включают в международные соглашения. К примеру, статья 2 Конвенции о защите морской среды северо-восточной части Атлантического океана 1992 года (OSPAR) требует, чтобы договаривающиеся стороны «применяли принцип материальной ответственности за загрязнение окружающей среды, благодаря которому затраты на меры по предотвращению загрязнения, борьбе с загрязнением и снижению уровня загрязнения должен нести загрязнитель».

Необходимо упомянуть о том, что Европейское сообщество официально приняло принцип материальной ответственности за загрязнение окружающей среды в 1973 году. Впервые речь о нем зашла

${ }^{8}$ The Dialogues of Plato: The Laws, vol. 4, book 8, section 485 (e), translated by Jowett B, Oxford: Clarendon Press (4th ed.), 1953. 
в Рекомендации ЕС от 3 марта 1975 года (Council Recommendation 75/436/EURATOM, ECSC, EEC of 3 March 1975, Annex, para 2 OJL 169, 29.6.1987. Р. 1): «Обязанность физических и юридических лиц, ответственных за загрязнение, оплатить затраты, необходимые для устранения загрязнения или до снижения последнего до нормативного уровня или оплатить эквивалентные мероприятия, которые дадут возможность достичь целевых показателей качества или, если такие показатели отсутствуют, дадут возможность удовлетворить нормативам или ограничениям, установленным органами власти».

21 апреля 2004 года Совет министров ЕС окончательно принял директиву об ответственности перед окружающей средой (2004/35/CE the Environmental Liability Directive, ELD), которая была включена в федеральное законодательство 25 государств - членов Европейского союза от 30 апреля 2007 года. Данная директива об ответственности перед окружающей средой обеспечивает выполнение принципа материальной ответственности за загрязнение окружающей среды внутри стран ЕС.

Принцип материальной ответственности за загрязнение окружающей среды был также включен в другие экологические договоры; сюда входят Конвенция Ассоциации государств Юго-Восточной Азии, 1985 (the ASEAN Convention), Альпийская Конвенция, 1991 (the Alps Convention), Конвенция ЕЭК ООН по охране и использованию трансграничных водотоков и международных озер, 1992 (the UN/ECE Transboundary Waters Convention), Конвенция об охране морской среды обитания в северо-восточной Атлантике, 1992 (the OSPAR Convention) и Конвенция по защите морской среды района Балтийского моря, 1992 (the Baltic Sea Convention).

В последнее время принцип материальной ответственности за загрязнение окружающей среды рассматривается как «способ интернализировать затраты, связанные с загрязнением в контексте экономической рационализации предприятия» ${ }^{9}$. Более того, данный принцип освобождает государство от возмещения затрат на предотвращение экологического ущерба, а также на восстановление окружающей среды, так как в противном случае финансовое бремя борьбы с загрязнением легло бы на плечи налогоплательщиков. Однако практика стран не требует, чтобы расходы на очистные мероприятия нес отдельный

\footnotetext{
${ }^{9}$ Stenis, Jan and William Hogland (2002). The Polluter-Pays Principle and its Environmental Consequences for Industrial Waste Management, Environment, Development and Sustainability Journal, Volume 4, Number 4 / December, 2002, Springer Netherlands.
} 
загрязнитель, в особенности в случаях, когда речь идет о международном разбирательстве.

Для того чтобы применить принцип материальной ответственности за загрязнение окружающей среды, необходимо доказать факт ответственности загрязнителя. В большинстве случаев для вменения обязательств относительно экологического загрязнения необходимо, чтобы (1) загрязнитель был выявлен, (2) ущерб был конкретным и поддающимся количественной оценке и (3) была показана причинная связь между (1) и (2). Чтобы доказать наличие ответственности и применить принцип материальной ответственности за загрязнение окружающей среды, должны быть соблюдены эти три условия. Ниже подробно описаны условия установления ответственности.

1. Загрязнитель должен быть выявлен: по общему правилу необходимо наличие возможности выявления ответственного загрязнителя. Обычно руководящее лицо (оператор) несет ответственность, если ущерб окружающей среде наносится по его вине. Директива об ответственности за загрязнение окружающей среды поддерживает положение о том, что ответственность за экологический ущерб, включая явную его угрозу, ложится на операторов ${ }^{10}$. Существуют следующие определения оператора, данные в различных конвенциях:

- лица, «осуществляющие контроль» над опасными видами деятельности, - статья 2(5) Конвенции Лугано 1993 г.;

- лица, «несущие ответственность» за опасные виды деятельности, - статья 1(е) Конвенции о промышленных авариях ЕЭК ООН 1992 г;

- государства, на территории которых ведется опасная деятельность (например, в случае с ядерной установкой), - статья 1(a), (c) Венской конвенции 1963 г.

В случаях, когда деятельность ведется компанией в форме юридического лица, ответственность ложится на лицо, несущее юридическую

${ }^{10} \mathrm{~B}$ соответствии с ELD оператор не обязан возмещать стоимость превентивных или восстановительных действий в случае причинения ущерба третьей стороной, несмотря на меры по обеспечению безопасности, принятые в соответствии с данным типом опасной деятельности, либо в случае, если ущерб являлся результатом действий по применению принудительных мер, предписанных государственным органом. Директива также предоставляет государствам - членам ЕС дискреционное право освобождения оператора от ответственности, когда действия, повлекшие за собой ущерб, были санкционированы государством, или когда оператор может предоставить свидетельство того, что выбросы или деятельность не представлялись вредоносными с научной и технической точки зрения в то время, когда они осуществлялись. 
ответственность, а не на работников компании, которые могли быть вовлечены в деятельность, послужившую причиной загрязнения. В некоторых случаях определяют так называемых первых и вторых ответственных лиц. В соответствии с новыми нормами по загрязненным землям в Великобритании, загрязнитель в первую очередь несет ответственность за ликвидацию ущерба окружающей среде; ответственность ложится на владельца земли или арендатора, в случае, когда загрязнителя установить невозможно. В некоторых странах, таких как Испания, Нидерланды, Финляндия, Швеция, Великобритания и Швейцария, существует теоретическая возможность установления ответственности компании-учредителя в сфере ее текущего влияния ${ }^{11}$. Американский Акт о гарантиях, ответственности, полной компенсации ущерба окружающей среде (CERCLA) предоставляет широчайшие возможности для установления ответственности. В соответствии с вышеуказанным актом к «потенциально ответственным сторонам» относятся: (I) действующие владельцы и операторы компании; (II) владельцы и операторы на период выброса опасных для окружающей среды веществ; (III) лица, организующие транспортировку и устранение таких веществ; и (IV) перевозчики опасных веществ.

2. Необходимо, чтобы ущерб был конкретный и поддающийся количественному измерению: ущерб окружающей среде должен быть конкретным и измеримым в денежном выражении или пригодным для количественной оценки. Довольно часто измерение ущерба носит спекулятивный и неточный характер, особенно в случаях, когда речь идет об экологическом ущербе. По этой причине задача количественной оценки экологических претензий часто вызывает излишние трудности. Очевидно, что размер компенсации должен рассчитываться в соответствии с корректной стоимостью очистки и восстановления участка, которому был нанесен ущерб (стандартный принцип материальной ответственности за загрязнение окружающей среды) или возмещением экологического вреда ${ }^{12}$. Но возникает вопрос: насколько разумно

${ }^{11}$ White Paper on environmental liability, COM (2000) 66 final 9 February 2000. Presented by the Commission European Commission.

12 Значение возмещения в международном праве выражено в Правиле Хожува, т.е. восстановление должно устранять все последствия незаконного действия и восстанавливать состояние, в котором бы, по всей вероятности, находилась окружающая среда, если бы это действие не совершалось. Такое возмещение взыскивается методами, которые международное право рассматривает как уместные, а именно: реституция в натуре, эквивалентная компенсация, удовлетворение претензий и обязательство 
со стороны истца требовать неограниченных расходов по устранению загрязнения и восстановлению территории? Существует ли граница, за которой дальнейшие попытки восстановления следует считать непропорционально дорогостоящими? Подобные вопросы поднимались в деле Содружество Пуэрто-Рико против судна «Зоуи Колоктрони» (дело «Зоуи Колоктрони») $)^{13}$. «Зоуи Колоктрони» было судном, вылившим нефть на побережье Пуэрто-Рико. Нефтяное пятно распространилось до бухты на побережье Пуэрто-Рико и нанесло ущерб мангровому лесу, расположенному на прилегающей заболоченной территории. Пуэрто-Рико и Совет по качеству окружающей среды (the Environmental Quality Board (EQB) подали иск о нанесении ущерба в адмиралтейский суд. Дело было направлено в суд, чтобы определить размер ущерба, нанесенного нефтяным пятном местной экосистеме, в денежном выражении. Суд постановил, что стоимость восстановления территории, которой был нанесен вред, до прежнего состояния не повлечет за собой несоразмерных затрат, а следовательно, может быть вменена в качестве санкции. Вследствие этого суд присудил Совету по качеству окружающей среды в первой инстанции 6 млн долларов США, 78 тыс. из которых шло в компенсацию стоимости очистки побережья от нефтяного пятна. Остаток средств был направлен на восстановление окружающей среды до прежнего состояния; стоимость повторной высадки мангровых деревьев составила 5 млн долларов, а стоимость замещения морских организмов, погибших в результате аварии, составила около 5,5 млн долларов. В данном случае суд постановил, что затраты «... должны быть приняты на себя сувереном либо его уполномоченным органом, с целью восстановить или преобразовать окружающую среду на пораженной зоне, вернув ее в прежнее состояние, либо на самой ближайшей к ней территории, не создавая непропорционально больших затрат. При назначении мер необходимо руководствоваться представлением о том, какие шаги предпринял бы разумный и предусмотрительный суверен или орган, чтобы снизить вредное влияние загрязнения с учетом таких факторов, как техническая обоснованность, опасность побочных эффектов, совместимость с естественной средой или ее экологическое дублирование, и того, в каких пределах

о несовершении действий, - примененные так, что все аспекты нанесенного ущерба устранены.

${ }^{13}$ Commonwealth of Puerto Rico v. S.S. Zoe Colocotroni, 456 F. Supp.1327 (1978); 628 F.2d $652(1980)$. 
принимаемые меры не окажутся избыточными или непропорционально дорогостоящими».

Более того, в данном случае окружной апелляционный суд США признал, что полная реставрация территории, которой был нанесен ущерб, физически невыполнима или неоправданно дорогостояща; более уместным будет принятие альтернативных мер, таких как воссоздание подобных условий окружающей среды на аналогичной близлежащей территории или на альтернативном участке. Идентичная реконструкция может быть невозможной; в таких случаях в последнее время появилась тенденция назначать принятие равносильных мер. В Зеленой книге Европейской комиссии «О возмещении экологического ущерба» говорится:

«Очевидно, что идентичная реконструкция может быть невозможной. Невозможно заменить исчезнувший биологический вид. Трудно изъять загрязняющие вещества, выброшенные в воздух или воду. Однако с точки зрения экологии необходимо ставить целью устранить последствия нанесенного окружающей среде ущерба и восстановить состояние окружающей среды если не до прежнего уровня, то по крайней мере так, чтобы защитить необходимые функции среды. ...Даже если восстановление или очистка осуществимы физически, они могут быть необоснованны с экономической точки зрения. Ожидать восстановления экосистемы, с которой взаимодействовали несколько поколений людей, до исходного состояния нерационально. Более того, восстановление окружающей среды до состояния, в котором она находилась до того, как ей был нанесен ущерб, может влечь за собой затраты, несопоставимые с желаемыми результатами. В таком случае можно признать, что меры по восстановлению необходимо принимать только до тех пор, пока они «эффективны с точки зрения затрат». Вынесение таких постановлений сложно из-за необходимости нахождения баланса между экономическими и экологическими ценностями» ${ }^{14}$.

Здесь необходимо упомянуть, что суд оставляет за собой право конечного решения, является ли «стоимость восстановления пораженного участка» или «стоимость воссоздания качества окружающей среды или эстетической ценности на альтернативном участке» нерациональной.

3. Необходимо установить причинную связь между ущербом и выявленным загрязнителем/загрязнителями. В большинстве случаев бремя

14 The Green Paper on Remedying Environmental Damage of the Commission of the European Communities COM (93) 47, p. 32, para. 5.2. 
доказывания вины лежит на истце. Это означает, что истец должен доказать, что обвиняемый причинил ущерб окружающей среде в виде загрязнения или существует «причинная связь» между загрязнением и загрязнителем. Если истцу не удается доказать наличие «причинной связи», суд допускает, что действия обвиняемого оказывают слишком незначительное влияние на окружающую среду и не могут послужить причиной загрязнения. Во многих странах суды снимают бремя доказывания, чтобы способствовать устранению загрязнения. Суды снимают бремя доказывания, когда совершаются «определенные опасные действия» или когда нет другого очевидного объяснения событиям, которые оспаривает в суде истец. Прецедент снятия бремени доказывания впервые имел место в Германии. Он требует от истца лишь доказательства возможности причинения экологического вреда определенным предприятием. В таком случае обвиняемый должен доказать, что реальной причиной загрязнения был другой источник. Таким образом, бремя доказывания падает на обвиняемого, и ему надлежит доказать, что он не виновен ${ }^{15}$. Суды в Китае также используют снятие бремени доказывания с истца. Это четко прописано в статье 4, разделе 3 Норм дачи показаний при рассмотрении гражданских исков в Верховном народном суде, где сказано: «В компенсацию исков, связанных с экологическим загрязнением, загрязнитель несет бремя доказывания, ...обязуясь предоставить свидетельство отсутствия причинной связи между действиями предприятиязагрязнителя и нанесенным вредом» ${ }^{16}$. Однако на практике многие суды по-прежнему требуют от истца предоставления свидетельств ${ }^{17}$. Из текста Директивы об ответственности перед окружающей средой ЕС 18 вытекает, что в тех случаях, когда чья-либо деятельность причиняет потенциальный ущерб окружающей среде, должен применяться принцип строгой ответственности. Это означает, что истцу достаточно показать причинную связь между деятельностью обвиняемого и нанесенным

15 The Green Paper on Remedying Environmental Damage of the Commission of the European Communities COM (93) 47, p. 32, para. 5.2.

16 Supreme People's Court Various Regulations Regarding Evidence for Civil Suits (promulgated by the Sup. People's Ct. Dec. 6, 2001, effective Apr. 1, 2002) Law Info China (last visited Mar. 19, 2007) (P.R.C.) (Alex Wang's translation, The Role of Law in Environmental Protection in China: Recent Developments by Alex Wang, Vermont Journal of Environmental Law Volume 8 2006-2007).

$17 \mathrm{Xu} \&$ Wang, supra note 46, at 103-104 (о количестве дел, в рассмотрении которых было отказано за несостоятельностью свидетельств).

18 ELD не рассматривает ущерб, причиненный выбросом, событием или инцидентом, произошедшим до 30 апреля 2007. 
ущербом, однако вина или халатность эксплуатирующей организации в доказательстве не нуждаются. Иными словами, вопрос не состоит в том, являются ли действия оператора или правонарушителя правомерными или неправомерными, но решающим показателем является факт нанесенного ущерба. Таким образом, абсолютная ответственность возлагает бремя доказывания на потенциального истца; это означает, что для установления ответственности он имеет право не доказывать умысел или халатность владельца компании. Однако он обязан предоставить в суде свидетельство того, что обвиняемый или оператор причинил ущерб окружающей среде. Абсолютная ответственность все же может предоставить некоторую защиту. Она заключается в следующем:

1) форс-мажорное обстоятельство или стихийное бедствие, которое часто определяют как «природные явления, имеющие исключительный, неизбежный и неудержимый характер» [1963 Vienna Convention, art. IV (3) (b); 1969 CLC, art. III (2) (a); 1977 Seabed Mineral Resources, art. 3(3); 1988 CRAMRA, art. 8(4); 1989 CRTD, art. 5(4) (a); 1993 Lugano, art 8(a); 1996 HNS, art. 7(2) (a); 1999 Basel Protocol, art. 4 (5) (b)];

2) военные действия [1963 Vienna Convention, art. IV (3) (a); 1969 CLC, art. III(2)(a); 1971 FUND, art. 4(2)(a); 1977 Seabed Mineral Resources, art. 3 (3); 1988 CRAMRA, art. 8(4); 1989 CRTD, art. 5(4)(a); 1993 Lugano, art 8(a); 1996 HNS, art. 7(2) (a); 1999 Basel Protocol, art. 4(5)(a)]; к войне или акту войны также обычно относятся вооруженный конфликт, гражданская война или мятеж;

3) действия третьей стороны [действия с намерением причинить ущерб, грубая халатность или упущения третьей стороны, 1969 CLC, art. 3(2) (b); 1989 CRTD, art. 5(4)(b); 1993 Lugano, art. 8(b); 1996 HNS, art. 7(2)(b); 1999 Basel Protocol, art. 4(5)(d)].

Кроме вышеперечисленных случаев, Луганская конвенция 1993 года освобождает обвиняемого от ответственности, если: (а) нанесенный ущерб явился результатом действий по применению принудительных мер, предписанных государственным органом. [Art. 8(c); 1999 Basel Protocol, art. 4(5)(c)]; (b) ущерб находится в допустимых пределах с учетом релевантных обстоятельств и (c) ущерб причинен в результате опасной деятельности, осуществленной на законных основаниях в интересах пострадавшего от данного ущерба лица [1993 Lugano Convention, art. 8(d), (e)].

Следует отметить, что экологическую ответственность легко установить, когда у ущерба имеется один или несколько идентифицируемых 
источников. Однако такую ответственность установить сложно, когда у ущерба существует множество пространственно-распределенных источников $^{19}$. Например, глобальное потепление является результатом множества воздействий, которые сложно выделить: выхлопы миллионов машин, воздействие кондиционеров, которые выделяют в атмосферу диоксид углерода и фреон.

Критерий доказанности часто описывают как «баланс вероятностей» или «преобладающую вероятность». В некоторых странах, таких как Бельгия, Португалия и Исландия, существуют более жесткие критерии доказанности.

Лицо, пострадавшее от любого вида экологического ущерба, обязано возбудить процесс против владельца компании в течение определенного срока; в случае необращения в суд в установленный срок данное лицо теряет право подачи иска. В различных конвенциях указываются неодинаковые сроки, в течение которых необходимо возбудить иск. Например, согласно Конвенции о международной ответственности за ущерб, причиненный космическими объектами, 1972 года [статья X (1)], пострадавшее лицо обязано подать иск на владельца производства в течение одного года, а согласно Луганской конвенции 1993 года, этот срок продлевается до 30 лет. Отсчет времени идет от фактической даты инцидента, в результате которого был нанесен вред окружающей среде. Однако если подвергшийся вредоносному влиянию пострадавший не осведомлен о нанесенном ему вреде и узнает об инциденте позднее, отсчет времени идет ото дня, когда пострадавший впервые получил сведения о: (a) существовании экологического вреда; (b) вероятном источнике вреда; (c) личности обвиняемого или обвиняемых.

Необходимо учитывать тот факт, что в соответствии с 1969 CLC, 1989 CRTD, 1993 Луганской конвенцией, 1996 HNS, судебное дело о получении компенсации должно быть возбуждено в течение трех лет со дня, когда лицу, предъявляющему претензию, стало известно или когда должно было стать известно в силу объективных обстоятельств о нанесенном ущербе и о личности загрязнителя ${ }^{20}$. Однако в со-

19 Пространственно-распределенные источники - множество мелких источников, способных выделять загрязняющие вещества в почву, воду и атмосферу, совокупное влияние которых на принимающую среду оказывается значительным.

20 Article 17(1), Convention on Civil Liability for Damage Resulting from Activities Dangerous to the Environment, Lugano, 21.VI.1993). 
ответствии с Луганской конвенцией судебные дела не будут возбуждаться по прошествии тридцати лет со дня инцидента, послужившего причиной загрязнения. В случае, когда загрязнение продолжалось в течение длительного периода времени, тридцать лет отсчитываются со дня его окончания. В случае, когда инциденты повторялись неоднократно, тридцать лет отсчитываются со дня последнего инцидента. Если речь идет о месте захоронения отходов, то тридцать лет отсчитываются не позднее чем со дня закрытия захоронения, определяемого в соответствии с нормами внутригосударственного права ${ }^{21}$.

Когда природному ресурсу, находящемуся в частной собственности, наносится ущерб, то в соответствии с законодательствами большинства стран владелец данного природного ресурса имеет право подать иск с целью получить возмещение от загрязнителя или потенциально ответственной стороны по суду. Когда речь идет о природном ресурсе, находящемся в общественной собственности, то встает вопрос: кто имеет право подачи иска о возмещении ущерба от имени общества? По традиции государство полномочно добиваться в суде возмещения ущерба, нанесенного природным ресурсам, так как оно несет ответственность по защите своих природных ресурсов на благо общества 22 . Так как долгом государства всегда является сохранение и защита природных ресурсов, доктрина parens patriae 23 позволяет государству (в качестве попечителя) добиваться этого в суде. Во многих государствах существует возможность подачи иска, позволяющего попечителю (государству) через суд добиваться восстановления территории, которой был нанесен ущерб, либо возмещения убытков 24 .

21 Article 17(2), Convention on Civil Liability for Damage Resulting from Activities Dangerous to the Environment, Lugano, 21.VI.1993).

22 Kanner, Allan (2005), The Public Trust Doctrine, Parens Patriae and the Attorney General as the Guardian of the State's Natural Resources, 16 DUKE ENVTL. L. \& POL'Y F. 57, 94-96 (Fall 2005).

23 Доктрина parens patriae (т.е. «родительского государства») в англо-саксонском праве уполномочивает государство защищать интересы своих граждан. С помощью дел parens patriae государства искали в суде возмещения ущерба «квази-суверенным» интересам». К таким «Квази-суверенным» интересам относятся общеэкономические или природоохранные интересы государства. Данная доктрина нашла применение в делах Late Corp. of the Church of Jesus Christ of Latter-Day Saints v. United States, 136 U.S. 1, 56 (1890); Wyoming v. Colorado, 286 U.S. 494, 509 (1932); Missouri v. Illinois, 180 U.S. 208, 241 (1901); Georgia v. Tenn. Copper Co., 206 U.S. 230, 238 (1907).

${ }^{24}$ Maine v. M/V Tamano, 357 F. Supp. 1097, 1098 (D. Me. 1973); Dep’t of Natural Res. v. Amerada Hess, 350 F. Supp. 1060, 1066-67 (D. Md. 1972); California v. S.S. Bournemouth, 
В действительности принцип материальной ответственности за загрязнение окружающей среды не всегда оказывается эффективным при борьбе с загрязнением. Он весьма эффективен, когда рассматриваемое загрязнение произошло в результате производственной деятельности, однако не приносит пользы в случае с историческим загрязнением. Теоретики права обнаружили у данного принципа следующие недостатки.

(a) Все еще не существует однозначного определения «загрязнителя». В юридической терминологии «загрязнитель»- некто, непосредственно или косвенно наносящий вред окружающей среде либо создающий условия для нанесения такого вреда. Ясно, что это определение настолько широко, что в некоторых случаях не имеет смысла. Например, господин Арьян является собственником компании BMW. Если компания BMW выбрасывает в атмосферу загрязняющий газ, то она несет непосредственную ответственность за выброс. Кроме того, производитель транспортных средств также несет косвенную ответственность за причинение экологического ущерба, как и розничный продавец автомобилей, и поставщик топлива, и государство, которое создает условия для нанесения ущерба окружающей среде, строя дороги и пренебрегая общественными транспортными нормами.

(b) Крайне трудно заставить загрязнителя нести «затраты на устранение загрязнения среды», в особенности когда у загрязнения есть несколько причин, существующих одновременно или последовательно, либо когда несколько предприятий работают на территории одного или нескольких государств и несут одинаковую ответственность за данное загрязнение. Более того, использование сложной технологии, опасных технологических процессов и множества токсичных материалов усложняет процесс установления ответственности. Потенциальный долговременный эффект аварии, все количество жертв, связь их заболеваний с загрязнением выявить весьма трудно.

(c) Юридическая ответственность за восстановление окружающей среды действительна в течение долгого срока и не снимается после устранения последствий экологического ущерба. Затраты на превентивные меры вменяются в пожизненную обязанность загрязнителю, и у него мало возможностей на это повлиять. Более того, чтобы спровоцировать

307 F. Supp. 922, 925 (C.D. Cal. 1969); Dep't of Envtl. Prot. v. Jersey Cent. Power \& Light Co., 336 A.2d 750, 759 (N.J. Super. Ct. App. Div. 1975), rev'd on other grounds, 351 A.2d 337 (N.J. 1976); State v. Bowling Green, 313 N.E.2d 409, 411 (Ohio 1974); Dep't of Fisheries v. Gillette, 621 P.2d 764, 766-67 (Wash. Ct. App. 1980). 
промышленную катастрофу «необходимо разработать технологию и наладить производство, а это требует огромного количества ресурсов, что в свою очередь обязательно подразумевает множество субъектов деяния. Это делает определение вины в традиционном судебном процессе еще более сложным, помогает обвиняемому бесконечно перекладывать вину со своих плеч на чужие» 25 .

(d) В разрешении спора по вопросам окружающей среды ключевым является фактор времени. Когда межтерриториальный экологический спор касается невинных жертв, часто населения развивающихся стран с ограниченными ресурсами, вопрос времени стоит весьма остро. Международные трибуналы зачастую выражают недовольство по поводу задержки в принятии мер, необходимых для разрешения экологического конфликта.

(е) Очень сложно заставить загрязнителя возместить нанесенный им экологический ущерб, подпадающий под межтерриториальную или единую юрисдикцию. Во многих случаях с целью избежать ответственности предприятие останавливает деятельность, осуществляет преобразование или попросту исчезает. Часто выявленный загрязнитель теряет возможность выплаты вследствие банкротства или неплатежеспособности. На данный момент правовые нормы по охране окружающей среды не дают решения в таких случаях. Таким образом, необходима транснациональная конвенция, которая бы решила юридические проблемы, существующие в области природоохранного права в отношении принципа материальной ответственности за загрязнение окружающей среды.

Несмотря на то что принцип материальной ответственности за загрязнение окружающей среды был провозглашен участниками раннего движения за охрану природы как средство сокращения экологического загрязнения, многие рассматривают его как «нечеткую идею». Есть мнение, что в соответствии с данным принципом загрязнитель выполняет свои обязательства, когда он возмещает по меньшей мере некоторую часть административных расходов служб, регулирующих виды деятельности, которые влекут за собой загрязнение. Существует также точка зрения, что обязательства могут быть признаны выполненными, только если загрязнитель возмещает всю стоимость устранения

${ }^{25}$ Cassels, Jamie(1993), The Uncertain Promise of Law: Lessons from Bhopal, 29 OSGOODE HALL L.J. 1, 2 (1991), Boston College International and Comparative Law Review, Summer, 1993. 
последствий загрязнения окружающей среды. И наконец, есть мнение, что необходимо облагать налогом пользователей природных ресурсов, деятельность которых ведет к загрязнению атмосферы (как, например, налог на выбросы углекислого газа).

\section{Библиографический список}

Barrett, Alan, John Lawlor, Sue Scott (editors) (1997), The Fiscal System and the Polluter Pays Principle: A Case Study of Ireland, Publisher: Ashgate - 1997 .

Deering, N., N.F. Gray (1989), Polluter Pays Principle: A Comparison of Charging Systems in Europe and the U.S.A., Publisher: Trinity College, Dublin, and 2nd edition - 1989.

Polluter Pays Principle: Definition Analysis Implementation, Author and Publisher: Organisation for Economic Co-Operation and Development - 1975.

Farmer, Andrew (1997), Managing Environmental Pollution, Publisher: Routledge - 1997.

Andrew, R.W. Jackson, Julie M. Jackson (2000), Environmental Science: The Natural Environment and Human Impacts, Publisher: Pearson Education Limited, Second Edition.

Polluter Pays Principle and Cost Recovery Charging, Author and Publisher: Parliamentary Office of Science \& Technology -1992.

Rubin, Conrad P., Eric J. Urbani (Author, Editor) (1994), Transnational Environmental Law and its impact on Corporate Behaviour: A Symposium on the Practical Impacts of Environmental Laws and International, Publisher: Juris Pub Inc.

Sand, Peter H. (1999), Transnational Environmental Law: Lessons in Global Change, Publisher: Kluwer Law International.

Pring, George, Ved P. Nanda (2003), International Environmental Law and Policy for the 21 st Century, Publisher: Transnational Publishers Inc., U.S.

Robinson, Martin Hedemann (2006), Enforcement of European Union Environmental Law: Legal Issues and Challenges, Publisher: Routledge Cavendish.

Louka, Elli (2006), International Environmental Law: Fairness, Effectiveness, and World Order, Publisher: Cambridge University Press; 1 st edition.

Scovazzi ,T., F. Francioni(1991), International Responsibility for Environmental Harm, Publisher: Kluwer Law International. 
Sands, Philippe, Paolo Galizzi (Editor) (2004), Documents in International Environmental Law, Publisher: Cambridge University Press; 2nd edition.

Wettestad, Jorgen (2002), Clearing the Air: European Advances in Tackling Acid Rain and Atmospheric Pollution, Publisher: Ashgate Publishing Limited.

Kibel, Paul Stanton (1999), The Earth on Trial: Environmental law on the international stage, Publisher: Routledge, (an imprint of Taylor \& Francis Books Ltd).

Keeble, John (1999), Out of the Channel: The Exxon Valdez Oil Spill in Prince William Sound, Publisher: Eastern Washington University Press.

Victoria Sherrow, (1998), The Exxon Valdez: Tragic Oil Spill (American Disasters), Publisher: Enslow Publishers.

Lebedoff, David (1997), Cleaning Up: The Exxon Valdez Case, the Story Behind the Biggest Legal Bonanza of Our Time. Publisher: Free Press, New York.

\section{Reemergence of Lost Paradigm: Polluter Pays Principle (Summary)}

\section{Abu Hena Mostofa Kamal*}

This article presents my personal narrative, in the epistemology of a new but mostly deserted subject 'Polluter Pays Principle'. It addresses the complex issues of transnational environmental law that have a profound relationship with Polluter Pays Principle. To give some context to the discussion, first portion of this article briefly discusses the definition of Polluter Pay Principle and its history. Further, it analyses the issues of liability, standard of proof that requires for establishing a polluting event, and its limitation period. It particularly focuses on the criticisms of Polluter Pays Principle. It is hoped that the results of this research would attract the attention of policy-makers, and rigorous legal safeguards should be implemented to protect the environment from future abuse.

Keywords: Polluter Pays Principle; environmental law; principles of transnational environmental law; pollution pay principle.

\footnotetext{
* Abu Hena Mostofa Kamal - Lecturer, Department of Law ASA University Bangladesh. gollancz75@yahoo.com.
} 